\title{
Non-Natural Born lecturers: \\ How to survive teaching in Dutch higher education
}

\author{
Oude Alink, Charlotte ${ }^{a}$; Martinetti, Alberto ${ }^{b}$; Karahanoğlu, Armağan ${ }^{b}$ and Hahnen- \\ Florijn, Marije ${ }^{\text {a }}$
}

${ }^{a}$ Centre of Expertise in Learning and Teaching, University of Twente, The Netherlands. ${ }^{\mathrm{b}}$ Design, Production and Management, Faculty of Engineering Technology, University of Twente, The Netherlands.

\begin{abstract}
Teaching in Higher Education Institutions (HEI) requests training and skills as researching. Unfortunately, on an international level the teaching training programme is not always crystal and clear, or even worse, not requested. Often researchers are asked to provide lectures without receiving proper formation. This approach creates sensible depletion in the educational quality. Offering an overview on how the Dutch HEIs are tackling the problem, the aim of this study is twofold: (i) presenting the University Teaching Qualification (UTQ) from a career development perspective and (ii) giving a qualitative evaluation of the entire process from the point of view of UTQ supervisors and lecturers. Finally concluding the relevance of such a professionalization programme.
\end{abstract}

Keywords: teaching qualification; non-natural born lecturers; professionalization; Dutch experience; Engineering Education 


\section{Researchers are not necessarily natural born lecturers}

Teaching, at every level, represents one of the most challenging and, at the same time, rewarding activity. Preparing students for living in the society, for being able to build a society and work in a multi-cultural team is both a responsibility and a pleasure. And, it requires never-ending efforts, in order to keep going to match the expectation of the society with the passions of the students. For this reason, skilled teachers are important for developing master courses based on Bloom's Taxonomy (Bloom, 1956) in order to be aligned with learning goals of the curricula and with the most recent innovations in terms of education.

As mentioned by Kelchtermans (2007), becoming a teacher is conceived of as a continuing process of professional development, resulting from the meaningful social interaction between the student teacher and his/her professional environment. However, it has to be said that, especially at higher education institutions as research universities, the path to become teacher or lecturer (or as academics like to be defined "professor") often begins with a strong research career orientation. As highlighted by Baume (2006) and confirmed by González-Geraldo \& Monroy (2017) learning to teach in higher education is not a straightforward path; teaching in higher education may be one of the last "non-professions".

In a nutshell: when working on a university people are trained to do research, and will also be heavily involved in teaching tasks. However, being an outstanding researcher, does not imply being a "natural born lecturer". Using a sporty simile, being a star player does not ensure to become a winning team manager. Looking at the European scenario, few countries are properly tackling this issue trying to incorporate next to a research training also an efficient teaching training. Due to pressure by the government and thanks to the ambition of universities a serious look was taken at the quality of education (Keesen et al., 1996). In 2008 this resulted in the agreement that all new incoming researchers have to professionalise themselves by obtaining a University Teaching Qualification (UTQ), "conditio sine qua non" for proceeding with their academic careers (de Jong, Mulder, Deneer \& van Keulen, 2013; Wiel et al., 2016).

Most lecturers who followed a teaching course to professionalize their teaching skills in higher education will experience positive effects in the long term (Stewart, 2013). Benefits that the lecturers experienced were more confidence in their teaching, a philosophy shift towards student-centred teaching, and an appreciation of getting in touch with another academic culture (Hanbury, Prosser \& Rickinson, 2008). Consequently, it is not a strange phenomenon that there is an increase in (obligatory) teaching courses when looking at the global developments (Hanbury, et al., 2008; Parson, Hill, Holland \& Willis, 2012). The success of a course depends on how the course is designed and implemented. A number of aspects that have a positive effect are: interventions spread over a longer time (Parson et al., 
2012), a connection to further professionalization/career perspective (Hanbury et al., 2008), and interaction with peers (Stewart, 2013).

Summarizing: it is important to professionalise researchers in their teaching, because these two different roles need two different skill sets. Several countries have adopted different rules about teacher professionalization and also universities within the same country have tackled this item differently. There are some success and failure factors known from literature. How does this knowledge influence the professionalization programmes available at Dutch Universities? And more important: does the UTQ help the lectures in their teaching tasks?

\section{How researchers can professionalize their teaching skills in the Netherlands}

The most standardized Dutch professionalization programme for teaching in Higher Education is the UTQ. And in 2008 all universities in the Netherlands signed an agreement which stated that they would recognize the UTQ of each other (de Jong, et.al., 2013; Wiel et al., 2016). This meant that if a teacher completed his UTQ at for example the University of Groningen, this certificate would also be valid at the University of Twente. A pro is that all lecturers who have their UTQ have at least the same basic skills, a con is that it limits the amount of freedom a university has to set-up their professionalization programme.

Nevertheless it does not mean that all universities have the same criteria for the UTQ or is supervised in the same way. There are similarities, for example that all lecturers have to hand in a portfolio which will be assessed. And there are differences, such as which lecturers are obligatory to get their UTQ, when lecturers have to start, or if it is obligatory to follow the courses.

The four technical universities in the Netherlands, called the 4TU have and additional agreement (the technical universities are: Technical University Delft (TUD), Technical University Eindhoven (TU/e), University of Twente (UT) and Wageningen University \& Research (WUR)) (van der Hulst et al., 2016). The TUD, TE/e and UT have this agreement since 2006 and WUR has joined this agreement since 2017.

The TUD, TU/e and UT already have the same criteria and WUR has the intention to join later on. Since 2017 new competences have been agreed upon by the 4TU, the universities have agreed to 5 different competences that lecturers have to obtain before receiving their UTQ (University of Twente, 2017). These competences are:

1. Designing or redesigning education

2. Teaching and Supervising

3. Assessment

4. Evaluating teaching

5. Professionalization 
For each of these competences, additional criteria have been formulated. The process differs again per university; in figure 1 the process of obtaining a UTQ at the UT is shown.

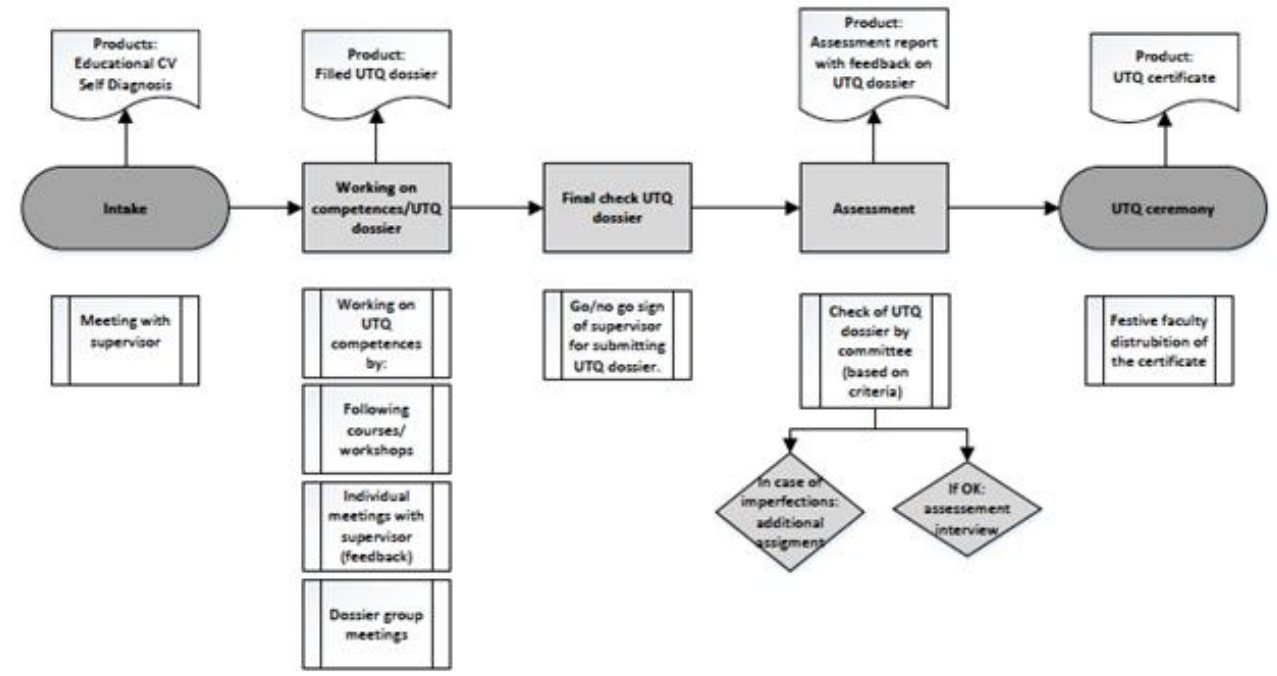

Figure 1. Process of the UTQ (University of Twente, 2017)

At the UT the estimated length of the process is set at 250 hours (University of Twente, 2017). The duration in which a lecturer finishes varies per person but in total the process should not take longer than three years. When a lecturer has received a positive result on the assessment, it is believed that the lecturer has shown that he has obtained the basic skills necessary to be a good lecturer in higher education. To make sure the quality of the portfolios are up to standard, the universities connected to the 4TU do random sample checks where they re-assess portfolios from the other universities once a year (van der Hulst et al., 2016).

On a national level, the quality of the lecturers is also monitored. Although lecturers are not obliged to get their UTQ by national law, at the 4TU universities most lecturers are "kindly" obliged to get their UTQ based on work experience and profile (van der Hulst, et al., 2016).

\section{How the UTQ works in practice}

a. The perspective from a UTQ supervisor at the University of Twente, faculty of Engineering Technology

The UT is divided into five faculties (1. Behavioural, Management and Social Sciences, 2. Electrical Engineering, Mathematics and Computer Sciences, 3. Engineering Technology, 
4. Science and Technology, and 5. Geo-Information and Earth Observation). Each faculty has one or two UTQ supervisors. Within the faculty of Engineering Technology there are two UTQ supervisors, both with background in educational science, and currently there are 24 lecturers in the UTQ process.

Each process starts with an intake interview in which the supervisor and the lecturer discuss the approach to take, competences and the educational tasks of the lecturer. At the UT the choice has been made to let the lecturer in the lead; the lectures decide if and how often he wants to meet the supervisor, which courses he wants to follow and on which educational tasks he wants to base his UTQ on. The UTQ supervisor does play an advisory role in this decision making indeed. One obligatory aspect is that the assignments need to be fulfilled by the lecturers in order to be connected to their own educational tasks. This way the lecturers learn the basic skills of teaching and improve their courses at the same time.

In the beginning of the process the lecturer follows several courses which are directly related to the five competences. During this time the contact between the supervisor and the lecturer is usually limited. When the lecturer starts with the writing process the contact intensifies. The supervisor gives one on one feedback on the chapters written by the lecturer and discusses the feedback during individual meetings.

Next to these individual meeting, there are a number of other group meetings, such as writing sessions, where the lecturers being away from their offices and other obligations can write and simultaneously consult with the supervisor. An additional helping moment is the UTQ-day, which is scheduled once a quartile. These meetings start with discussing theoretical educational content and continues in a writing session.

When the lecturers are ready writing their portfolios they can ask their supervisor to perform a final check for completeness. Then, the lecturer hands in the portfolio for the assessment and the UTQ-coordinator assembles an assessment committee, consisting of the programme director of the programme the teacher is connected to, an educational advisor (other than the UTQ supervisor). The supervisor of the lecturer can clarify small things, but does not have an active role in the assessment. First the portfolio is read and the assessment is finalized with an assessment interview.

Table 1. Overview of the number of lecturers in the UTQ trajectory.

\begin{tabular}{|l|l|l|}
\hline Position in the trajectory & Absolute numbers & Percentages \\
\hline Certified & 310 & $41,0 \%$ \\
\hline Have an equivalent & 118 & $15,6 \%$ \\
\hline In the trajectory & 121 & $15,9 \%$ \\
\hline Still need to start & 77 & $10,2 \%$ \\
\hline Have an exemption & 131 & $17,3 \%$ \\
\hline
\end{tabular}


At the moment, 26,1\% of the lecturers are working on their UTQ or still need to start (see table 1). Since February 2018 a questionnaire was set out to the lectures who finished their UTQ. In total 13 lecturers filled in the questionnaire. 76,9\% of the lecturers evaluated the UTQ trajectory as 'good', the other $23,1 \%$ of the lectures answered 'neutral'. Most lectures indicated that the UTQ have contributed to their teaching skills to a large extend $(53,8 \%)$. They state that the UTQ especially has provided them with tools/methods on how to educate. The voluntary courses were mentioned most often as the most useful element of the UTQ and writing the portfolio as the least useful element.

Interesting here is that also some lecturers mentioned the complete opposite; indicating that the courses were too broad (not specified for their specific discipline), and writing the portfolio forced them to properly think about their courses. All in all, these results prove that the UTQ process is a very individual one, therefore it is relevant to zoom in on the experience of two lecturers, one still in the process and one who has obtained his UTQ.

\section{b. The University of Twente, faculty of Engineering Technology}

As stated, lecturers who start working at UT are obliged to finalize their portfolio within 3 years. The competences of UTQ are designed to help the lecturer to learn and reflect on various dimensions of teaching in higher education. Starting from the "designing and redesigning of education", the UTQ process contributes to the improvement of both the experience of the lecturer and the quality of teaching at the university.

Based on the reflections of the authors, lecturer's experience before starting the UTQ process varies. Some of the lecturers have prior knowledge and even experience in completing a "teaching qualification portfolio". That is mainly because, improving the quality of teaching in higher education has been a world-wide phenomenon. While the structure of the process might be different for every lecturer, the aim of all teaching qualification portfolios is approximately the same. For instance, in one of the universities that authors previously worked, the PhD and Post-Doc's take courses for improving their teaching quality in higher education, developing a course and lecture plans before they get a certificate. Therefore, the lecturers who have this prior knowledge might feel more confident in starting and handling the process. Still, the UTQ is different than any other course that international universities offer and unique in covering all the dimensions of teaching in higher education which helps the lecturers to reflect on their teaching.

The UTQ process shows several contact points with the well-known Bloom's Taxonomy approach. Figure 2 explains how the "non-natural born lecturers" can perform the five competences of the UTQ adopting the educational objectives of the taxonomy as backbone for each one of those. 


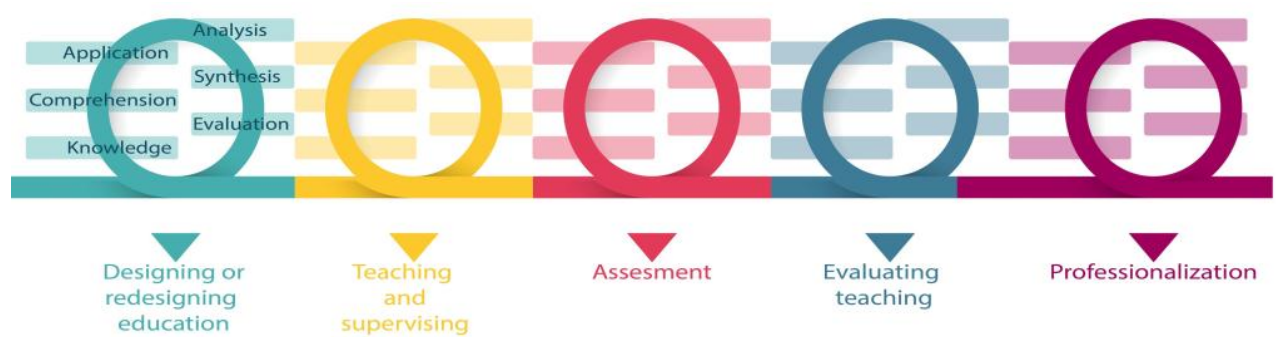

Figure 2. How Bloom's Taxonomy is integrated in the 5 UTQ competences.

Referring to the first UTQ competence, "Designing (or re-designing) a course", it is highly important for lecturers to start with "knowing" and "comprehending" the contextual information and the pedagogical requirements of the course within a study programme. Once the lecturer has the proper confidence with the needed information (expected students' level, workload of the course, assessment criteria), she/he can translate the gained knowledge in practice, "applying" it in designing a course.

After that, an "analysis" phase gives to the lecturer the opportunity to test whether the set general learning requirements are met in the design she/he made. Based on these results changes can be "synthesised" in the following times the course with be executed. Finally, the lecturer has to "evaluate" her/his own role in the design process of the course.

The role of the researcher is not forgotten in the UTQ process. The lecturers are also expected to do research in addition to their teaching duties. This helps the lecturer to look from a different perspective: how could we integrate the research experience and knowledge into the topics of the lectures. This does raise the challenge, namely to communicate the complexity of the knowledge with the students through appropriate teaching methods. Therefore, UTQ process assists the lecturers to learn those methods and implement their professional research skills and knowledge into their teaching.

\section{Conclusions}

University Teaching Qualification (UTQ) is a standardized Dutch professionalization programme that aims at improving the educational needs of higher education. This paper outlines the reflections of supervisors and lecturers on the process.

UTQ offers a tool to improve the personal learning skills in higher education. The process is evaluated positively by most lecturers. The results obtained during the UTQ sessions force the lecturer to learn how to get more students' engagement, how to create collaborative socialization, how to supervise and give proper and constructive feedback increasing at the same time the own educational competences. These competences are related not only to how to build and organise a course, but also in general to the challenges 
related to supervising students. What could strengthen the process is to have the courses more specified to the disciplines of the different lecturers.

Moreover, the UTQ offers a relevant opportunity to let the lecturers apply and experience different strategies, to reflect on eventual teaching mistakes and possible points to improve, understanding the reasons behind them during the discussion sessions. The feedback that lecturers receive about their progress during the UTQ development make them feel almost always more confident (or shows them they still need to work hard).

\section{References}

Baume, D. (2006). Towards the End of the Last Non-Professions? International Journal for Academic Development, 11(1), 57-60.

Bloom, B.S. (1956). Taxonomy of educational objectives. New York: David McKay.

de Jong, R., Mulder, J., Deneer, P. \& van Keulen, H. (2013). Poldering a teaching qualification system in higher Education in the Netherlands: a typical Dutch phenomenon. Revista de Docencia Universitaria, 11(3), 23-40.

González-Geraldo, J. L. \& Monroy, F. (2017). Impact of a teacher development programme on approaches to teaching in higher education. 3rd International Conference on Higher Education Advances, HEAd'17, Universitat Politecnica de Valencia, Valencia. DOI: http://dx.doi.org/10.4995/HEAd17.2017.5052.

Hanbury, A., Prosser, M. \& Rickinson, M. (2008). The differential impact of UK accredited teaching development programmes on academics' approach to teaching. Studies in Higher Education, 33(4), 469-483.

Kelchtermans G. (2006). Teacher collaboration and collegiality as workplace conditions. A review, Zeitschrift für Pädagogik, 52, pp. 220-237.

Keesen F., Wubbels T., van Tartwijk J. \& Bouhuijs P.A.J. (1996). Preparing university teachers in The Netherlands: Issues and trends, International Journal for Academic Development, 1 (2), pp. 8-16. https://doi.org/10.1080/1360144960010202.

Parsons, D., Hill, I., Holland, J. \& Willis, D. (2012). Impact of teaching development programmes in higher education. Report from the The Higher Education Academy. Retrieved from: https://www.heacademy.ac.uk/system/files/resources/hea_impact_teaching_developmen t_prog.pdf.

Stewart, M. (2013). Making sense of a teaching programme for university academics: Exploring the longer-term effects. Teaching and Teacher Education, 38, 89-98. 
University of Twente, CELT. (2017). UTQ Manual: University Teaching Qualification. Report from University of Twente, CELT. Retrieved from: https://www.utwente.nl/en/ces/celt/utq/utq-manual-deelnemers-dec-2017.pdf.

University of Twente. (n.d.). In Homepage University of Twente. Retrieved 29th of January 2018, from https://www.utwente.nl/en/organization/structure/

van der Hulst, J., Weltje-Poldervaart, M., Pauw, E., Rijnbeek, G., van de Wouw, H., van Eck-de Vries, W., Hahnen, M. \& Sjerps, M. (2016). 4TU Regulations. Report from 4TU. Retrieved from: https://www.utwente.nl/en/ces/celt/utq/4tu-utq-regulation-def-uk08-03-17.pdf. 